\title{
Karl Marx e a economia política: da rejeição moral à assimilação crítica
}

\author{
Karl Marx and the Political Economy: \\ From Moral Rejection to Critical Assimilation
}

\author{
Henrique Wellen ${ }^{a}$ \\ (D) https://orcid.org/0000-0002-4787-5918
}

\begin{abstract}
Resumo: Buscou-se analisar, de forma breve, elementos históricos, teóricos e políticos que consubstanciaram o trânsito da relação entre Karl Marx e a economia política. Para tanto, destacou-se a relação dos sentidos das categorias de trabalho abstrato e de força de trabalho com o evolver dessa dinâmica, demarcado por três momentos centrais: uma crítica de teor filosófico e moral; a aceitação da teoria ricardiana dos salários; e uma assimilação crítica, propulsora de uma análise econômica inovadora.
\end{abstract}

Palavras-chave: Karl Marx. Economia política. Força de trabalho. Trabalho abstrato.

\begin{abstract}
We tried to analyze historical, theoretical and political elements that composed the transit of the relationship between Karl Marx and political economy. To do that, the relationship between the meanings of the categories of abstract work and the labour power was highlighted with the evolution of this dynamic, marked by three central moments: a critique with philosophical and moral content; the acceptance of the Ricardian theory of wages; and a critical assimilation, propelling an innovative economic analysis.
\end{abstract}

Keywords: Karl Marx. Political economy. Labour power. Abstract work. 
fato bastante conhecido e debatido que a formação do pensamento de Karl Marx passou por momentos distintos e por algumas inflexões. Como é natural em todo grande pensador, a assimilação de novos conhecimentos não ocorreu, em Marx, de forma imediata nem linear. Dos seus primeiros estudos e publicações sobre filosofia até os seus últimos textos econômicos, a trajetória de Marx se apresentou a partir de várias conexões e embates teóricos, metodológicos e políticos.

Não foram poucos os pensadores que ele leu e analisou. Também não foram poucas as ideias criticadas e nem foram escassos os autores repreendidos por ele. Quando se analisa, por exemplo, o seu envolvimento com o campo da economia política, essa verve ferina também fica bem explicitada.

O objetivo central deste artigo voltou-se para a análise, ainda que de forma breve, de elementos históricos, teóricos e políticos que consubstanciaram o trânsito dessa relação entre Karl Marx e a economia política. Nesta análise, destacou-se a relação dos sentidos das categorias de trabalho abstrato e de força de trabalho com o evolver dessa dinâmica.

\section{II}

Se, por um lado, pode-se perceber, ao longo das obras de Marx, um mosaico de críticas e agravos, por outro lado também se observam, ainda que em número bem inferior, exemplos de admiração intelectual. Alguns pensadores figuraram numa posição de apreciação bastante elogiosa por Marx. Claro que, como um impenitente iconoclasta, Marx não se furtou à análise crítica de nenhum desses autores. De toda forma, podem-se indicar dois nomes que se relevam nesse limitado elenco de pensadores explicitamente admirados por Marx: Aristóteles e Hegel.

O respeito por Aristóteles aparece em vários momentos, inclusive quando Marx indica determinações históricas e sociais que justificam 
limites na análise econômica do pensador grego (Marx, 2010a). Já em relação a Hegel, o posicionamento de Marx é ainda mais explícito. Tal fato se observa, por exemplo, no posfácio, escrito no início de 1873, à segunda edição alemã de $O$ capital. Nesse texto, Marx (2010b, p. 19) não apenas se posiciona radicalmente contra aqueles que tratavam Hegel como um "cachorro morto", como também afirma que "abertamente me confessei um aluno deste poderoso pensador". 1

Já no que concerne à especificidade da economia política, isto é, aos teóricos clássicos desse campo de conhecimento, um autor, em especial, recebe uma carga superior de julgamento: David Ricardo. Como consta no texto anteriormente citado, logo depois de afirmar que a economia política "pertence ao período em que a luta de classes era ainda pouco desenvolvida”, Marx (2010b, p. 13) indica que Ricardo foi "o seu último grande representante”. Além disso, Marx (idem) afirmou que "Ricardo, no final, de forma consciente, toma o antagonismo dos interesses de classe, de salários e lucros, de lucros e aluguel, como o ponto de partida de suas investigações, [ainda que] ingenuamente tomando esse antagonismo por uma lei social da natureza".

Ou seja, mesmo que Marx identifique limites na análise de Ricardo (ingenuamente tomando esse antagonismo por uma lei social da natureza), ele não se furta à sua consideração elogiosa. Não obstante, a grandeza intelectual do pensador inglês seria comprovada também pela fidedignidade realista da sua análise. Ainda que se tratasse claramente de um intelectual conectado com os anseios da burguesia industrial inglesa, ${ }^{2}$ Ricardo não teria, segundo Marx, se isentado da análise de contradições econômicas e de antagonismos de classes originados do modo de produção capitalista.

Além disso, Marx (2010b, p. 19) também afirmou que, ao menos nos capítulos iniciais de O capital, ele havia claramente se inspirado no método expositivo de Hegel.

2 Uma das principais peças de análise econômica de Ricardo e que teve uma finalidade política foi o seu Essay on the Influence of a Low Price of Corn on the Profits of Stock (Um ensaio sobre a influência do preço da lei dos cereais nos lucros do estoque). 0 artigo de Ricardo (2004, p. 4), "foi um dos muitos panfletos que foram preparados, em antecipação dos debates na Câmara dos Comuns, sobre a questão das Leis dos Cereais". 
Com qualidades perscrutadoras tais como essas, Ricardo, além de ser um pensador dotado de elevada qualidade analítica, seria também portador de uma honestidade intelectual. Por ter, por exemplo, exposto contradições presentes na relação entre capital e trabalho, Marx (2010c, p. 355), nos seus rascunhos de 1861-63, atesta para a "imparcialidade científica de Ricardo". Nesse sentido, Marx (2010c, p. 347), em algumas páginas antes dessa afirmação, critica alguns pensadores, como Sismondi, que não levaram em conta a justeza da análise de Ricardo sobre o desenvolvimento produtivo, esquecendo que a "produção, por si só, não significa nada além do desenvolvimento das forças produtivas humanas ou, em outros termos, que o desenvolvimento da riqueza da natureza humana como um fim em si mesmo".

Contudo, esse nem sempre foi o julgamento de Marx sobre o principal representante da economia política clássica e nem sobre a sua obra teórica. Quase duas décadas antes da afirmação anterior, quando Marx estava em Paris, imerso nos seus primeiros estudos sobre a economia política, ${ }^{3}$ a sua visão era muito diferente. Um exemplo disso se encontra no seu artigo intitulado "Glosas críticas marginais ao artigo 'O rei da Prússia e a reforma'", que foi publicado em 31 julho de 1844 no Vorwärts! Pariser Deutsche Zeitschrift, um jornal de pensadores alemães exilados em Paris. Nesse texto, Marx (2010d, p. 192) se refere ao economista inglês como "o cínico Ricardo". ${ }^{4}$

3 Primeiros estudos no sentido direto, de contato com obras específicas da economia política. Anteriormente, esse contato ocorreu de forma indireta, com destaque para as análises das obras de Hegel, que, dentre outras coisas, foi estudioso da economia política.

4 Sobre esse fato, Mandel (1971, p. 43) afirma que, "apesar do rigor da expressão polêmica, Marx está, aqui, começando a defender Ricardo contra seus críticos, a entender que o que parece ser o cinismo é realmente um reconhecimento franco das realidades do modo de produção capitalista, que outros escritos buscam ocultar". Contudo, duas páginas depois dessa afirmação, Mandel (1971, p. 45) volta a analisar a mesma admoestação de Marx a Ricardo de uma forma distinta. E, mesmo que se considerasse, nesse caso específico, a validade da observação de Mandel, o mesmo não se aplicaria para outras passagens da obra de Marx. Nesse momento da sua vida, a visão geral que Marx tinha da economia política era bastante negativa, e isso abarcava a totalidade dos seus integrantes, como demonstra, por exemplo, a seguinte citação: "a escola 
Outras considerações de teor semelhante também podem ser encontradas nos rascunhos preparados por Marx durante esse período. Em seus chamados Manuscritos econômico-filosóficos encontram-se várias recriminações contra o economista político inglês. Nas palavras de Marx (2010e, p. 256), “para Ricardo, os homens não são nada e o produto é tudo". Além disso, os adjetivos usados por Marx (2010e, p. 291) nessa obra se encontram em sentido oposto ao que ele utilizou vários anos depois: existe "um crescimento relativo no cinismo da economia política de Smith através de Say para Ricardo, Mill etc., na medida em que as implicações da indústria parecem mais desenvolvidas e mais contraditórias aos olhos dos últimos pensadores".

As abordagens de Marx expostas sobre Ricardo, portanto, variaram bastante. Entre os escritos de 1844 e as anotações de 1861-63 decorreram quase duas décadas, e Marx passou de 26 para 45 anos. Ele transitou de um jovem iniciante nos estudos da economia política a um pesquisador incansável sobre as minúcias e os avanços das análises desse campo de conhecimento.

Essas alterações do julgamento de Marx foram muito além da superação de arroubos juvenis ou de coisas desse tipo. Da mesma forma, essas inflexões não se estabeleceram em torno da gradativa negação de ideias de transformação social. Além de outros fatos, a trajetória da formação política de Marx não ocorreu em direção a um reformismo ou a um posicionamento conservador perante a ordem social estabelecida. Pelo contrário, o desenvolvimento do seu pensamento pautou-se pelo contínuo aprofundamento das análises das contradições centrais do modo de produção capitalista. E a motivação política teve grande relevo nessa empreitada. ${ }^{5}$

Say-Ricardo é hipócrita em não admitir que é precisamente a extravagância e o capricho que determinam a produção" (Marx, 2010e, p. 310).

5 Um dos exemplos que explicitam não apenas a manutenção da visão revolucionária de Marx, mas a sua gradativa análise das condições concretas para esse objetivo é a comparação entre o seu histórico e a trajetória teórica e política de Proudhon (cf. Netto, 2004). 


\section{III}

Inicialmente, nas suas primeiras análises sobre a economia política, Marx enxergava essa ciência centralmente como uma forma de naturalização do modo de produção capitalista. E, nesse sentido, ocorria a sua rejeição em relação às ideias e à própria figura de David Ricardo. No início dos anos de 1840, Marx negava, por exemplo, que o fundamento do valor das mercadorias advinha do trabalho e concordava com as afirmações de Proudhon de "que o aluguel e o lucro são 'superadicionados' e, portanto, são fatores que terminavam gerando um aumento no preço" das mercadorias (Mandel, 1971, p. 41).

Mas, com o decorrer do tempo, essa posição de Marx em relação aos princípios da economia política foi se alterando, com destaque para a relação com a teoria do valor-trabalho. Um dos fatos que conduziu Marx a uma reflexão sobre isso adveio da utilização política dessa teoria. No início de 1845, Marx firmou um contrato com C. W. Leske (um editor de Darmstad - Alemanha) para a publicação de um livro sobre a Crítica da política e da economia política. O material inicial que Marx desejava utilizar para essa empreitada eram os seus manuscritos escritos em Paris. Mas, ciente das suas limitações sobre estudos e pesquisas na área da economia política, Marx entendia que precisava de elementos teóricos e empíricos para basear a realização do seu projeto.

Nesse sentido, ele empreendeu uma viagem de Bruxelas (onde esteve exilado entre 1845 e 1848) para a Inglaterra. Engels serviu como seu guia de viagem e lhe fez a aproximação tanto com novas obras da economia política como com agrupamentos de trabalhadores. Foi na Inglaterra que Marx se deparou com um fato que lhe pareceu inusitado: a utilização de ideias e análises das obras de Ricardo por escritores socialistas ingleses, descobrindo, então, "o uso revolucionário-social" da economia política (Mandel, 1971, p. 45).

$\mathrm{Na}$ Inglaterra, em meados dos anos 1840, pensadores radicais e organizações da classe trabalhadora começaram a se utilizar da premissa 
central da economia política clássica de que todo valor econômico advém do trabalho. ${ }^{6}$ Dessa forma, "se o trabalho, de fato, 'produziu tudo', estes escritores estavam perguntando por que eles [trabalhadores] também não deveriam receber tudo - ou, ao menos consideravelmente mais do [recebem] que no presente?" (Meek, 1973, p. 166).

Quando tais ideias começaram a ter uma grande utilização social, elas se tornaram uma arma contra a legitimação do capitalismo. Diante disso, no momento em que pensadores conservadores se depararam com essa forma de uso da teoria do valor-trabalho, tornou-se praticamente inevitável advertir para os perigos sociais do pensamento de Ricardo. A explicitação desses dois lados políticos acerca da disputa sobre a herança teórica de Ricardo apontou, em Marx, para a necessidade de repensar as suas críticas sobre o maior representante da economia política inglesa.

Mas ainda que esse fenômeno tenha impactado Marx, outros elementos também foram decisivos para a sua inflexão acerca da economia política. Os seus estudos e pesquisas avançavam rápido e ele lia vorazmente os principais autores dessa ciência. Por tudo isto, sem demorar muito tempo, Marx transitou de uma posição de rejeição moral da economia política para a sua assimilação teórica. E isso ocorreu, em especial, com as análises de Ricardo (Wellen, 2019).

A partir de 1847, com a publicação da Miséria da filosofia, Marx (2010f) acabou por externar a aceitação e a utilização das ideias de Ricardo. Observa-se, nessa obra, uma inversão da adesão de Marx entre os polos de disputa teóricos apresentados três anos antes. Se, em 1844, Marx se filiava às críticas de Proudhon contra Ricardo, em 1847 ele fez exatamente o contrário (cf. Marx, 2010f, p. 121).

Essa obra de 1847, ao lado das suas outras principais obras econômicas escritas entre o fim de 1846 e o início de 1848 , demonstra a

6 Sobre a utilização inicial da teoria do valor-trabalho e das ideias de Ricardo a partir da posição política da classe trabalhadora, destacam-se as análises realizadas por William Thompson e por Thomas Hodgski (cf. Hunt, 2005). 
mudança no pensamento de Marx acerca da economia política. Nesse período, Marx e Engels publicaram quatro obras centrais que incidiam diretamente na análise econômica: Miséria da filosofia, de 1847 (Marx, 2010f); Princípios do comunismo, de 1847 (Engels, 2010b); “Trabalho assalariado e capital" de 1847 (Marx, 2010g7) e o Manifesto do Partido Comunista de 1848 (Marx e Engels, 2010b). Como afirma Mandel (1971, p. 52), essas quatro obras possuem uma análise econômica "praticamente idêntica" e que "contêm a primeira análise crítica, em termos gerais, do modo de produção capitalista”.

Nessas obras, Marx e Engels ressaltaram o contraditório desenvolvimento do modo de produção capitalista, que tanto gera riqueza para o lado dos capitalistas como pobreza para o lado dos trabalhadores. Esse pressuposto de análise se manteve até os últimos textos dos dois pensadores alemães. Contudo, a forma de abordagem acerca desse fenômeno passou por algumas mudanças. Se, nesse momento, existia uma tendência de tratar esse fenômeno de forma absoluta, com o andamento das análises sobre o modo de produção capitalista, eles passariam a destacar mais o caráter relativo dessa desigualdade.

A análise sobre a pobreza, inicialmente, tinha o seu exame direcionado por termos lineares e absolutos. $\mathrm{Na}$ análise dessas obras citadas, observa-se que o aumento da riqueza dos capitalistas geraria, de forma quase mecânica, o aumento da pobreza dos trabalhadores. Assim, dentro do modo de produção capitalista, o horizonte vislumbrado para a classe trabalhadora era de pauperização iminente e gradativa. É também nesse sentido que se deve interpretar a frase magna que fecha o panfleto político mais famoso da história da humanidade: "os proletários não têm nada a perder, além das suas correntes” (Marx e Engels, 2010b, p. 519).

\footnotetext{
Esse texto de Marx (“Trabalho assalariado e capital") foi publicado em 5 de abril de 1849, no Neue Rheinische Zeitung. Contudo, o material utilizado para a preparação deste texto data de dezembro de 1847, quando Marx estava dando palestras sobre economia política na Sociedade de Trabalhadores Alemães em Bruxelas. Desse material utilizado em 1847 restou um texto de Marx (2010g) intitulado "Salários", que "é quase idêntico ao que foi publicado posteriormente no Neue Rheinische Zeitung” (Marx e Engels, 2010a, p. 560).
} 
Claro que, por se tratar de um manifesto político, esse texto de Marx e Engels possui uma forma analítica menos restrita do que as obras econômicas stricto sensu. Ainda que apresente ideias, modelos e análises sobre a conjuntura história, o Manifesto do Partido Comunista tem, no seu cerne, um chamamento político. Para usar um jargão bastante repetido, esse tipo de texto volta-se para corações e mentes. Contudo, toda proposta de intervenção política conecta-se com determinada assimilação teórica. E, especialmente no caso de Marx, guias políticos deslocados de análises profundas da realidade apenas serviriam para o retrocesso mistificador das lutas sociais. ${ }^{8}$

Por isso a ideia do pauperismo absoluto, de que o proletariado iria gradativamente se tornar mais pobre ao passo que mais riqueza fosse produzida, se assenta em determinada leitura econômica da realidade. Trata-se, essencialmente, de indicar que a condição econômica do proletariado, independentemente da produção social de riqueza, não iria ascender. E, para tanto, o salário dos trabalhadores representa o elemento mais importante dessa tendência. Ao direcionar para o pauperismo absoluto do proletariado, Marx e Engels estavam indicando também que a degradação das condições econômicas dessas pessoas seriam, no seu cerne, determinadas pelos valores dos salários.

Essa análise da realidade deriva, em grande medida, das assimilações acerca da economia política. Nesse período da vida, Marx tinha saltado de uma rejeição moral da economia política para uma aproximação seletiva

8 A permanente busca de novos conhecimentos científicos que servissem de auxílio na análise da sociedade era uma marca da personalidade de Marx. Ao lado dessa qualidade se somavam o temperamento explosivo e uma tendência de afirmação de superioridade intelectual. Tudo isso se externava conjuntamente quando a meticulosidade científica era posta em questão, como demonstra um caso narrado por Annenkov: "Ao ouvir essas últimas palavras, Marx finalmente perdeu o controle de si mesmo e bateu com tanta força com o punho na mesa que a lâmpada tocou e sacudiu. Ele deu um pulo dizendo: 'A ignorância nunca ajudou ninguém!'. Seguimos o exemplo dele e saímos da mesa. A sessão terminou, e enquanto Marx andava de um lado para o outro da sala, extraordinariamente irritado e zangado, eu rapidamente me despedi dele e de seus interlocutores e fui para casa, maravilhado com tudo que eu tinha visto e ouvido" (McLellan, 1995, p. 141). 
(cf. Wellen, 2019, p. 20). Nesse movimento de aproximação, Marx tinha selecionado Ricardo como o seu principal interlocutor e aderido a alguns dos seus princípios teóricos. Um dos principais pressupostos teóricos de Ricardo, que advém na esteira de economista políticos anteriores, era a ideia de que o salário dos trabalhadores operava como em uma relação entre um preço natural e um preço de mercado:

O trabalho, como todas as outras coisas que são compradas e vendidas, e que podem ser aumentadas ou diminuídas em quantidade, tem seu preço natural e de mercado. $O$ preço natural do trabalho é aquele preço que é necessário para permitir que os trabalhadores, um depois do outro, subsistam e perpetuem sua raça, sem aumento ou diminuição. (Ricardo, 2001, p. 58)

Nessa perspectiva, os valores dos salários seriam determinados pelas oscilações do mercado e regulados pela relação entre oferta e demanda. Esse seria, por sua vez, o preço de mercado do trabalho. Mas, nessa concepção, apesar dessas oscilações, existiria um mínimo em que esses valores poderiam chegar. Esse valor mínimo, que representa aquilo que é indispensável para a reprodução física do trabalhador, é o preço natural do trabalho. Como a tendência, dentro da relação entre oferta e demanda no mercado de trabalho, era de aumentar a quantidade de trabalhadores, a lei dos salários apresentaria a diminuição gradual do preço de mercado do trabalho. Por causa dessa tendência, o preço de mercado do trabalho seria rebaixado permanentemente ao seu preço natural.

Na Miséria da filosofia, Marx (2010f, p. 125) acompanha essas ideias de Ricardo e afirma que "o preço natural do trabalho não é outro que não o salário mínimo". ${ }^{9}$ De forma semelhante, isso também fica explicitado, em momentos diferentes, no Manifesto do Partido Comunista:

9 Engels afirmou, na nota de rodapé incluída para a edição alemã de 1885 dessa obra, que Marx (2010f, p. 125), nesse período, aceitava essa tese da economia política, seguindo um texto do próprio Engels (2010a), publicado em 1844. Nos estudos posteriores, especialmente em O capital, Marx (2010a) reviu essa tese, indicando as possibilidades históricas e sociais de alteração dessa tendência, situando os salários tanto para cima como para baixo dos seus valores. 
"Esses operários, que devem vender-se aos poucos, são uma mercadoria como qualquer outro artigo de comércio e, consequentemente, estão expostos a todas as vicissitudes da competição, a todas as flutuações do mercado" (Marx e Engels, 2010b, p. 490); ou "o custo de produção de um operário é restrito, quase inteiramente, aos meios de subsistência que ele requer para sua manutenção e para a propagação de sua raça”. Da mesma forma,

o operário moderno, pelo contrário, em vez de se elevar com o progresso da indústria, afunda cada vez mais abaixo das condições de existência de sua própria classe. Ele se torna um pobre, e o pauperismo se desenvolve mais rapidamente que a população e a riqueza. (Marx e Engels, 2010b, p. 495)

A análise econômica tendencial apresentada por Marx (e Engels) nesse período era, pois, a de pauperização contínua da classe trabalhadora. Em termos absolutos, quanto mais riquezas fossem produzidas pelo modo de produção capitalista, mais as condições de vida do proletariado sofreriam pioras. Diferentemente de obras econômicas posteriores, em que Marx ressalta as diferenças entre pauperismo absoluto de pauperismo relativo, a utilização acrítica de elementos da economia política não lhe permitiu, nesse momento, apreender corretamente alguns elementos dessa contraditória dinâmica produtiva.

De toda forma, a aderência a esse postulado da economia política terminava por distanciar a análise da economia da esfera da produção para a esfera da circulação. Ricardo indicou que o valor das mercadorias era determinado pela quantidade de trabalho dispendido na sua produção. Contudo, ao analisar o valor do trabalho, esse pensador terminou relacionando com o preço do trabalho, isto é, o salário. E, para fazer esse cálculo (dos salários), seria necessário analisar os preços das mercadorias ofertadas no mercado, que comporiam aquilo que era necessário para manter a subsistência do trabalhador. Por isso que, na análise da economia política para determinar a fonte do valor econômico, ocorreria um trânsito da esfera da produção para a esfera da circulação. 
Todavia, com o prosseguimento dos estudos e das análises dentro da economia política, dois grandes avanços foram realizados por Marx.

\section{IV}

Nos primeiros estudos de 1844, Marx apresentou uma rejeição da economia política, realizando uma crítica externa a esse campo do conhecimento. Em seguida, como demonstram as citações anteriores, Marx passa por um processo de adesão a determinados postulados da economia política. No momento seguinte, que se explicitou no final dos anos 1850, ele começou a realizar uma crítica a partir das contradições internas dessa ciência.

Nessa época (final dos anos de 1850), Marx tanto incrementou a análise da produção de valor econômico como apresentou um avanço no exame dos salários. Para tanto, ele buscou aprofundar a análise do valor na esfera da produção e, assim, passou a diferenciar não apenas o preço de mercado do preço natural, mas, essencialmente, valor e preço. Da mesma forma, apresentou, a partir da utilização de categorias usuais da economia política, uma diferenciação entre o trabalho e a força de trabalho.

Conforme afirma um dos seus principais biógrafos, são nos seus estudos e anotações iniciadas no final de 1850 que se encontra "a primeira elaboração da teoria madura de Marx" (McLellan, 1995, p. 281). Esse material, conhecido como Grundrisse, apresenta duas modificações centrais em relação às ideias anteriores de Marx:

Primeiro, em vez de analisar os mecanismos de troca do mercado (como fizera em 1844), ele agora partia de uma consideração da produção. Em segundo lugar, ele agora disse que o que o trabalhador vendia não era seu trabalho, mas sua força de trabalho. Foi uma combinação dessas duas visões que deu origem à doutrina da mais-valia. (Idem)

Ainda segundo McLellan (1980, p. 70), esse período, “de 1857 a 1859” teria sido, "de várias maneiras, o mais produtivo da vida de Marx". Foi 
durante essa fase que Marx escreveu quatro importantes obras: a "Introdução geral à sua proposta dos seis volumes econômicos" (1857); "um rascunho que, posteriormente, recebeu o título de Esboços de uma crítica da economia política" (1857-58, também conhecido como Grundrisse); o "Prefácio" (1857-59); "e os primeiros poucos capítulos da obra intitulada de Para a crítica da economia política” (1858-59, ou Contribuição à crítica da economia política) (Idem).

Realmente esse período da vida de Marx foi de grande importância para o desenvolvimento do seu pensamento e para a formulação da sua crítica à economia política. Não obstante, nos parece mais conveniente ampliar um pouco esse espaço temporal para, assim, poder dar conta de outras obras importantes de Marx sobre este tema. Entre 1857 e 1863, Marx produziu três grandes amontoados de rascunhos. Esse material, ao lado da sua Contribuição à crítica da economia política, publicada em 1859, demonstram as análises e as conexões teóricas que Marx estava realizando nesse momento e que foram tão importantes para a construção do seu Magnum Opus publicado em 1867.

Entre 1857 e 1958, Marx produziu os seus Esboços da crítica da economia política (Grundrisse der Kritik der Politischen Ökonomie). Logo depois, entre 1861 e 1863, ele começou a preparar o material que serviria de continuação para a sua obra publicada em 1859 (Contribuição à crítica da economia política). Para tanto, preparou, entre 1861 e 1863, os rascunhos integrantes dos chamados Manuscritos econômicos. E, finalmente, entre 1862-1863, realizou um conjunto de análises sobre a história da economia política que, depois, ficariam conhecidos como Teorias da mais-valia (Theorien über den Mehrwert) e que foram publicados, entre 1905 e 1910, por Karl Kaustky, como sendo a continuação de 0 capital (1867). ${ }^{10}$

10 Em seus estudos e pesquisas, Marx, classificava as etapas de seu processo teórico tanto pelo seu caráter analítico como pela sua forma expositiva. 0 material final, pronto para ser publicado, precisaria ultrapassar o cunho de análise e se estabelecer pelas suas qualidades expositivas: "É claro que o método de apresentação deve diferir em forma do [método] de investigação. Este último deve apropriar-se do material em detalhes, para analisar suas diferentes formas de desenvolvimento, para traçar sua conexão interna. Somente após esse trabalho ser feito, o 
De toda forma, foi, entre o final dos anos de 1850 e o início de 1860 que Marx realizou grandes avanços na análise da economia política. A partir desse período, pode-se afirmar que ele ingressou em um novo nível qualitativo em relação a esse campo do conhecimento. Inicialmente, a partir de 1843-44, ele realizou uma rejeição que continha, de forma privilegiada, valorações morais à economia política. Em seguida, a partir do final de 1846, Marx passou a reproduzir premissas da economia política e, em especial, da análise de Ricardo sobre a relação entre os valores dos salários e das mercadorias. E, a partir de 1857, com a preparação dos Grundrisse, Marx encaminhou uma análise mais profunda acerca da taxa de lucro e da concorrência entre os capitais (cf. Mandel, 1971, p. 87-88). Esses avanços em relação à economia política permitiram a Marx problematizar alguns pressupostos desse campo do conhecimento.

A economia política apresentava as diferenças entre valor de uso e valor de troca, assim como entre preço de mercado e preço de custo. No cerne dessa questão se encontrava, ao menos no maior representante dessa teoria (Ricardo), a vigência da teoria do valor-trabalho, que indicava que o valor de qualquer mercadoria era determinado pela quantidade de trabalho dispendido na sua produção. Também em relação à análise do trabalho como fonte de valor, já se utilizava, dentro da economia política, a categoria da força de trabalho. Contudo, tanto a análise do valor do trabalho como a utilização da categoria da força de trabalho receberam, a partir da assimilação crítica de Marx, diferentes abordagens.

movimento real pode ser descrito adequadamente. Se isso for feito com sucesso, se a vida do sujeito é idealmente refletida como em um espelho, então pode parecer como se tivéssemos antes de nós uma mera construção a priori" (Marx, 2010b, p. 19). Junto com esse movimento se localizava, também na concepção metodológica de Marx, a distinção entre a apresentação da "história da ciência" da exposição da "ciência da história". Esta se organiza a partir das qualidades específicas internas do objeto para, por meio disto, apresentar as conexões entre os distintos elementos analisados. Já a "ciência da história" se vale de explicações de enredamento histórico, demarcando-se por acontecimentos e os seus efeitos. Seguindo essas terminologias, enquanto os livros I, II e III de $O$ capital apresentariam a ciência da história, os livros seguintes, conhecidos como Teorias da mais-valia, exporiam a história da ciência. Ressalta-se ainda que, pelo que foi afirmado anteriormente, o caminho indicado para leitura das duas obras é o inverso do caminho de escrita. 
Seguindo as pegadas da economia política, tem-se que o valor de troca das mercadorias é determinado pela quantidade de trabalho. Mas, com isso, tinha-se outra questão: qual o valor de troca do próprio trabalho? Dentro desse campo de conhecimento, ao se analisar o valor de troca do próprio trabalho, terminou-se por indicar que os salários dos trabalhadores eram determinados pelas mercadorias consumidas para a sua manutenção. Assim, criou-se, em certa medida, um ciclo vicioso, em que o valor de troca dos trabalhos passou a ser derivado do valor de troca das mercadorias (que tinham seus valores determinados pelos trabalhos).

Para tentar dar respostas a esse imbróglio, Marx precisou também colocar em questão algumas categorias da economia política, da mesma forma que necessitou alterar o sentido de outras. O sentido usual do termo força de trabalho era empregado, dentro da economia política, tanto como uma capacidade do trabalhador em realizar o processo produtivo, como pela quantidade de trabalhadores aptos e disponíveis para integrar esse processo.

Foi assim também que, durante muito tempo, Marx e Engels correntemente utilizaram essa categoria. Todavia, quando Marx se deparou com a necessidade de avançar na análise da determinação do valor dentro do modo de produção capitalista e, consequentemente, com a investigação do valor do trabalho, ele apresentou um novo sentido para essa categoria.

A partir de junho de 1865, quando Marx proferiu algumas palestras no Conselho Central, em Londres, já se pôde observar a apresentação desse novo sentido para a categoria força de trabalho. No material utilizado para as palestras, intitulado "Valor, preço e lucro (Value, price and profit), Marx (2010g, p. 128) indicou que "o que o operário vende não é diretamente o seu trabalho, mas a sua força de trabalho, a disponibilidade temporária que ele produz para o capitalista".

Não obstante, esse termo (força de trabalho - Arbeitskraft) já tinha sido apresentado alguns anos antes, sob outra formulação, mas mantendo um sentido próximo ao de 1865. No já citado Grundrisse de 1857-58, Marx (2010h e 2010i) indicava essa ideia a partir de uma nomenclatura 
distinta: capacidade de trabalho (Arbeitsvermögen). Alguns anos depois, entretanto, a utilização dessa categoria, mesmo apresentando sentidos originais, seguiu, nas obras de Marx, a nomenclatura clássica da economia política. Se, nesses rascunhos de 1857-58, Marx concilia o uso da categoria capacidade de trabalho (Arbeitsvermögen) com a categoria força de trabalho (Arbeitskraft), em $O$ capital ele apresentará a categoria da força de trabalho como a energia física e mental que o trabalhador possui e que a utiliza sempre que produz algum valor de uso (cf. Marx e Engels, 2010c, p. 536).

Ao analisar os sentidos da categoria da força de trabalho, visualiza-se que essas variantes utilizadas por Marx se conectaram diretamente com as diferentes concepções apresentadas acerca do trabalho abstrato. Essa observação ganha relevância especialmente quando se analisam os rascunhos desse período da vida de Marx, em que se apresenta uma teia de relações, tanto diretas como indiretas, entre essas categorias. Nesse material, as relações entre essas categorias se apresentam a partir de um conjunto de mediações e de sentidos bem largos. Desde a análise da vigência do valor de troca, que universaliza as mercadorias e o próprio trabalho no processo produtivo, à alienação que abarca as diversas ações dos trabalhadores, a relação entre trabalho abstrato e força de trabalho se faz presente.

Ao comparar, nessa obra, as análises desses múltiplos conectores teóricos elencados por Marx, com importantes obras econômicas anteriores e posteriores, revelam-se processos de inflexões teóricas. Por exemplo, observam-se significativas diferenças entre os sentidos da força de trabalho e do trabalho abstrato em obras juvenis, como os Manuscritos econômico-filosóficos, e em obras mais maduras de Marx, como O capital.

Inicialmente, o emprego da categoria trabalho abstrato direcionava-se, em essência, para a denúncia filosófica de uma sociedade dominada pela propriedade privada e pela divisão social do trabalho. Nesse contexto, o ser humano estaria mediado por processos de alienação e o trabalho operaria como um sacrifício externo que, na contramão da sua potência 
social, impossibilitaria a realização humana. O trabalho abstrato, dessa forma, expressaria a anulação das qualidades sociais e objetivas do ser humano subordinado a essa produção.

A ideia de abstração, que, inicialmente, sob perspectiva filosófica e antropológica, recebia uma conotação pejorativa, aparece, em obras maduras de Marx, direcionada para uma utilização metodológica distinta. Nessas obras posteriores, releva-se o emprego da abstração como um procedimento metodológico essencial para a análise social e, em especial, para a sociedade dominada pelo modo de produção capitalista (cf. Marx, 2010b, p. 8). A importância da categoria do trabalho abstrato, por sua vez, se ressalta tanto na indicação de elementos históricos inéditos, quanto no anúncio de uma unidade qualitativa entre as distintas formas concretas de trabalhos.

No fundo, a modificação ocorrida no tratamento dessas categorias segue, de forma direta, as inflexões que Marx teve em relação à análise da economia política. Por isso que, a nosso ver, a forma como Marx utilizou essas categorias explicita também uma diferença na sua relação com a economia política. Demonstrar as diferenças nos seus sentidos empregados dessas categorias é, pois, uma forma de indicar continuidades e inflexões na formação do pensamento econômico de Marx.

\section{Referências}

ENGELS, Frederick. Outlines of a Critique of Political Economy. In: MARX, Karl; ENGELS, Frederick. Collected Works (Karl Marx March 1843-August 1844). Londres: Lawrence \& Wishart, 2010a. v. 3.

Principles of comunism. In: MARX, Karl; ENGELS, Frederick. Collected Works (Marx and Engels 1845-48). Londres: Lawrence \& Wishart, 2010b. v. 6.

HUNT, E. K. História do pensamento econômico: uma perspectiva crítica. 2. ed. Rio de Janeiro: Elsevier, 2005.

MANDEL, Ernest. The Formation of the Economic Thought of Karl Marx, 1843 to Capital. Nova York: Monthly Review Press, 1971. 
MARX, Karl. Capital: a Critique of Political Economy. V. I, Book. I, The process of production of capital. In: MARX, Karl; ENGELS, Frederick. Collected Works. (Karl Marx - Capital Volume I). Londres: Lawrence \& Wishart, 2010a. v. 35.

Afterword to the Second German Edition. In: MARX, Karl; ENGELS, Frederick. Collected Works. (Karl Marx - Capital Volume I). Londres: Lawrence \& Wishart, 2010b. v. 35 .

Economic Manuscript of 1861-63. Theories os Surplus Value. In: MARX, Karl; ENGELS, Frederick. Collected Works (Marx 1861-63). Londres: Lawrence \& Wishart, 2010c. v. 31.

Critical marginal notes on the article "The King of Prussia and Social Reform". In: MARX, Karl; ENGELS, Frederick. Collected Works (Karl Marx March 1843-August 1844). Londres: Lawrence \& Wishart, 2010d. v. 3.

Economic and Philosophic Manuscripts of 1844. In: MARX, Karl; ENGELS, Frederick. Collected Works (Karl Marx March 1843-August 1844). Londres: Lawrence \& Wishart, 2010e. v. 3.

The Poverty of Philosophy. Answer to the Philosophy of Poverty by M. Proudhon. In: MARX, Karl; ENGELS, Frederick. Collected Works (Marx and Engels 184448). Londres: Lawrence \& Wishart, 2010f. v. 6.

Wages. In: MARX, Karl; ENGELS, Frederick. Collected Works (Karl Marx March 1843-August 1844). Londres: Lawrence \& Wishart, 2010g. v. 3.

Outlines of the Critique of Political Economy (Rough draft of 1857-58) First Instalment. In: MARX, Karl; ENGELS, Frederick. Collected Works (Karl Marx 1857-61). Londres: Lawrence \& Wishart, 2010h. v. 28.

Outlines of the Critique of Political Economy (Rough draft of 1857-58) Second Instalment. In: MARX, Karl; ENGELS, Frederick. Collected Works (Karl Marx 1857-61). Londres: Lawrence \& Wishart, 2010i. v. 29.

MARX, Karl; ENGELS, Frederick. Collected Works (Marx and Engels 1849). London: Lawrence \& Wishart, 2010a. v. 9.

Manifesto of the Communist Party. In: . Collected Works (Marx and Engels

1844-48). Londres: Lawrence \& Wishart, 2010b. v. 6.

Collected Works (Marx 1857-61). London: Lawrence \& Wishart, 2010c. v. 29.

MCLELLAN, David. Karl Marx: a Biography. Londres: Papermarc, 1995.

The Thought of Karl Marx. 2. ed. Londres: Papermarc, 1980.

MEEK, Ronald. Studies in the Labour Theory of Value. 2. ed. Nova York, Londres: Monthly Review Press, 1973. 
NETTO, José Paulo. 1847: Marx contra Proudhon. In: Marxismo impenitente: contribuição à história das ideias marxistas. São Paulo: Cortez, 2004.

RICARDO, David. Essay on the Influence of a Low Price of Corn on the Profits of Stock. In: The Works and Correspondence of David Ricardo. (Pamphlets and Papers 1815-1823). Editado por Piero Sraffa com a colaboração de M. H. Dobb. Indianapolis: Liberty Fund, 2004. v. IV.

On the Principles of Political Economy and Taxation. 3. ed. Ontario: Batoche Books, 2001.

WELLEN, Henrique. 1843-44: Marx e Engels e a rejeição filosófica e moral da economia política. In: Revista Novos Rumos. v. 56, n. 1, 2019. p. 1-22.

\section{Sobre o autor}

Henrique Wellen - Pós-doutor em Teoria Política (University of Kent, Inglaterra) e doutor em Serviço Social. Docente da graduação e da pós-graduação em Serviço Social da Universidade Federal do Rio Grande do Norte.

E-mail: harw@uol.com.br 